\title{
Gambling Addiction Defence on Trial: Canadian Expert Witness Perspectives
}

\author{
Garry Smith ${ }^{*}$ and Rob Simpson
}

\author{
University of Alberta, Edmonton, AB T5J 4P6, Canada
}

\begin{abstract}
The American Psychiatric Association's evolving recognition of pathological gambling as a behavioral addiction (DSM-III, 1980; DSM-V, 2013) has occasioned increased use of the gambling addiction defence in criminal trials. Reflecting upon our experiences as expert witnesses in criminal and civil liability proceedings where gambling addiction was a significant factor, we a) describe the expert witness role; b) examine the links among frequent and intense EGM play, gambling addiction, and financially-based crimes; c) review how revisions to the Diagnostic and Statistical Manual influenced the Canadian judicial system response to such crime; and d) explore prospects for reducing criminal activity by addicted EGM players. We discuss how and why gambling addiction has become generally accepted as a mitigating factor in Canadian criminal trials. In this commentary we also analyze how the plight of addicted gamblers who resort to criminal behavior might be remediated by a) gambling-specific consumer protection measures; b) tighter regulatory control over the addictive elements of EGM play; c) the implementation of gambling courts; and d) a legislated duty of care owed by gambling providers to EGM players.
\end{abstract}

Keywords: Gambling addiction, expert witness, diminished capacity, rehabilitative sentences.

\section{INTRODUCTION}

Under the Criminal Code of Canada, gambling is legal only when "conducted and managed" by provincial governments, all ten of which have embraced the opportunity. In 2011-12, the proliferation of Gambling in Canada netted an after-winnings total of \$14 billion nation-wide (Canadian Gambling Digest, 2011-2012). Collateral harm from this activity, which results in large part from gambling addiction, is an inescapable consequence, and viewed as a cost of doing business that needs to be managed (Livingstone and Woolley, 2007). Accordingly, gambling distinguishes itself as the only government supported activity that knowingly harms those it was elected to serve (Simpson, 2012).

Increasingly, problem gambling has become viewed as a significant criminogenic factor. Research on correctional populations indicates "gambling issues are apparent in approximately a quarter to a third of offenders, depending on study sample size and problem gambling screening tool used" (Perrone, Jansens and Morrison, 2013: 24). Owing to the systematic under-reporting of gambling-related crime ${ }^{1}$, however, these percentages are considered conservative (Smith, Wynne and Hartnagel, 2003).

*Address correspondence to this author at the University of Alberta, 2-394 Enterprise Square, 10230 Jasper Ave., Edmonton, AB T5J 4P6, Canada; Tel: (780) 492-2770; Fax: (780) 492-6735; E-mail: garry.j.smith@ualberta.ca

${ }^{1}$ For example, a person who steals money in an attempt to win back gambling debt will be charged with theft and, although the frequency and amount of money involved will be recorded, there may be no identification of the gambling-related motive.
This article reflects upon our experiences as expert witnesses in criminal and civil liability proceedings where gambling addiction was a significant factor. Its purpose is fourfold:

1. To describe the expert witness role.

2. To examine the links among frequent and intense electronic gambling machine (EGM) play, ${ }^{2}$ problem gambling, and financially-based crimes.

3. To review how changes to the Diagnostic and Statistical Manual influenced the judicial system's response to such crime.

4. To explore prospects for reducing criminal activity by addicted EGM players.

To circumvent debates over terminology, we employ two interchangeable terms: "problem gambling" and "gambling addiction." "Problem gambling" refers to a disorder characterized by impaired control over gambling, attendant negative consequences, and persistence in harmful and unsustainable gambling. Of particular concern are moderate-to-high severity problem gamblers; who are more likely to come into conflict with the law. Our analogous use of "gambling addiction" aligns with the fifth edition of the Diagnostic and Statistical Manual (DSM-V, 2013) of the American

${ }^{2}$ EGMs refer to both VLTs (video lottery terminals) and slot machines. Although the machines are identical, in Canada they are distinguished by location. VLTs are found in premises with liquor licenses (bars and lounges), whereas slot machines are located in designated gambling venues (casinos and racetracks) (Smith and Campbell, 2007: 87). 
Psychiatric Association (APA), which classifies gambling problems under the category of addictions.

This commentary fills a gap in the literature by examining the gambling addiction defence in Canadian criminal trials from the perspective of expert witnesses, supplemented by similar experience in liability actions against gambling providers. More specifically we focus on EGM play, which is the dominant form of gambling in criminal cases, and has the greatest harm potential for the population at large (Livingstone and Woolley, 2007; Munoz, Chebat and Suissa, 2010).

\section{THE LINK BETWEEN PROBLEM GAMBLING AND CRIME}

The criminal behavior of problem gamblers is frequently characterized as "out of character" and inconsistent with an otherwise law-abiding person. Typically, these people hold jobs, have families, lead relatively normal lives, and have no prior criminal history. All started out as recreational gamblers, and their transition to problem gambling was usually an incremental process. This evolution is made explicit in cases where the offender is a loyalty program member. Initially, the loyalty program data base reflects low risk play - often in the order of a few hours per month or two and modest bets of between five cents and a dollar per spin. Over time, increases become apparent in relation to frequency of play, duration of sessions, and bet size as the individual moves well beyond normative play and into a range more consistent with problem gambling ${ }^{3}$.

Gambling providers rigorously monitor loyalty data and, based on money wagered, provide members with inducements ("comps") designed to increase the frequency and duration of sessions and, of greatest concern, overall money wagered. The anticipated scale of EGM play is illustrated by the three membership levels of the "Winner's Circle" program operated in Ontario (Ontario Lottery and Gaming, 2014). Members betting under $\$ 10,000$ per year have no identified status; those betting between $\$ 10,000$ and $\$ 49,999$ in the program's terms "earn" silver status; and those who bet in excess of $\$ 50,000$ annually achieve gold status.

\footnotetext{
${ }^{3}$ Contemporary EGMs permit the playing of multiple lines for each bet. For example, betting 15 -lines at 25 cents each cost $\$ 3.75$ per 5 -second spin. By using the stop button, players can reduce the spin time to as little as one second, thereby requiring $\$ 225$ in bets per hour of play, or $\$ 1,800$ over an 8hour duration. Playing at these rates over 20 days per month would require $\$ 432,000$ in bets per year.
}

Loyalty programs recognize no upper limits in relation to how much a player can lose. Arising from a freedom of information request, the Toronto Globe and Mail reported Winner's Circle data from a single EGM venue in Ontario (Priest, 2009). The highest recorded annual "net loss" was $\$ 701,117$ for a player who visited the venue 294 times and bet an average of $\$ 2,385$ per visit. The second highest was $\$ 635,921$ lost over 92 visits and an average of $\$ 6,912$ per visit. The top 10 loyalty program members averaged annual net losses of $\$ 455,555$ or $\$ 38,796$ per month. In Australia, the Productivity Commission (2010) found that $2.6 \%$ of a casino loyalty program's membership generated $76 \%$ of its revenue.

It is not surprising that the synergistic effects of EGM design and loyalty programs produce players who consistently wager more than intended. For some, such over-spending will involve the reallocation of money designated for other purposes--food, housing, utilities or car payments-losses of this nature are, by definition, unaffordable and create financial crisis. At this point, financial duress and the confluence of erroneous cognitions, preoccupation with gambling, and impaired control result in gamblers "chasing losses" to win back the needed money. It also marks the onset of desperation gambling, a downward spiral that inevitably leads to more losses and mounting urgency for a redemptive win. Reason succumbs to emotion as players resort to rash acts such as credit card advances, cashing in retirement savings or drawing on lines of credit. As these resources deplete a state of torment emerges, where the now severelyaddicted gambler faces an insurmountable financial problem and no options for its resolution.

With some variation in the specifics, these typify the circumstances under which the line to illegal activity is crossed. Financial misappropriations of whichever type are rationalized as loans which will be repaid when the money is won back; hope for redemption hinges on beating overwhelmingly unfavorable odds to deliver the rarest of jackpots.

Certainly, EGM addicts must bear responsibility for their actions, as understanding the circumstances of their behavior is not tantamount to condoning it. However, courts should also recognize that just as there are problem gamblers, there are problem machines, problem gambling environments, and problem business practices (Dow Schull, 2012). The gambling addiction process most commonly reveals a causal chain that extends beyond the vulnerability of 
individuals to the material contribution of gambling providers.

\section{AN OVERVIEW OF EGM PLAY AND POTENTIAL HARM}

The risk of gambling-related harm is higher for EGMs than for all other forms of gambling and their attributes permit providers to take advantage of vulnerable players through a "gradual and insidious process" (Borrell, 2006: 183). Though their addictive potency is well known, EGMs are nonetheless actively promoted by governments (Orford, 2009) and represent the dominant revenue stream from gambling operations in Canadian provinces (Canadian Gambling Digest, 2011-2012). Of note, gambling providers' potential contribution to the harm of patrons in many ways parallels that of on-premise alcohol consumption, and yet there is no corresponding legislative or civil duty of care to protect gamblers from being exploited or victimized (Simpson, 2004; Sasso and Kalajdzic, 2006; Smith and Rubinstein, 2011). Finally, an Australian study has demonstrated "a consistent positive and significant relationship between EGM play and crime rates, especially income-generating crime rates at the local level" (Wheeler, Round and Wilson, 2011: 315).

Recent research in the province of Alberta, Canada provides an illustrative overview of EGM play. Although only $21 \%$ of adults play EGMs in a given year, they account for $84 \%$ of total provincial gambling revenue (Williams, Belanger and Arthur, 2011; Alberta Gaming and Liquor Commission 2012-2013). Further to this imbalance, problem gambling rates are 3 to 4 times higher for EGM players than for other gambling formats (Williams, et al., 2011). Finally, the $4 \%$ of Albertans who qualify as problem gamblers generate over $50 \%$ of EGM revenue (Williams, et al., 2011: 110). Similar patterns can be found across all Canadian provinces where Harrigan and MacLaren (2011: 17) found EGMs to be the leading format for problem gamblers.

Dow Schull (2012: 21) posits that the objective of EGM manufacturers is "to get people to gamble longer, faster and more intensively...to turn casual players into repeat players." Accordingly, EGM designers aim to maximize what is referred to as REVPAC - revenue per available customer (Dow Schull, 2012). The endpoint for REVPAC is known as "playing to extinction," which occurs when the player's available funds in a given session are depleted (Institute for American Values, 2013). This design objective is, of course, antithetical to the responsible gambling mantra of setting and staying within limits.
The Productivity Commission (2010: 4, 24) observed that all harm-inducing properties of EGMs are exposure related and, therefore, enhanced by government policy-mandated easy access and widespread availability (Storer, Abbott and Stubbs, 2009; Thomas, Allen and Phillips, 2009). Specific harm-inducing attributes include a) machine structural characteristics (e.g., alluring sounds and graphics, fastpace, intermittent reinforcement, and programmed near misses) (Parke and Griffiths, 2006; Turner and Horbay, 2004); b) the generation and reinforcement of erroneous cognitions (e.g., that players can influence outcomes, that jackpots are due to occur, or not recognizing that small wins can actually be disguised losses) (Harrigan et al., MacLaren, Brown, Dixon, \& Livingstone, 2014; Delfabbro and Winefield, 2000); and c) the facility for delivering players into an immersive, mindless, distraction-free state (Livingstone, 2005; Dow Schull, 2012). In the six criminal trials of addicted gamblers where the first author served as an expert witness, all accused were EGM players who had tendered guilty pleas to non-violent financial crimes such as fraud, theft, or embezzlement.

\section{DIMINISHED CAPACITY AND DSM RECOGNITION OF PATHOLOGICAL GAMBLING}

An ongoing legal debate has centered on whether gambling addiction constitutes diminished capacity for the purpose of assigning criminal responsibility (Starr, 2003; Samson, 2004; Geis, 2004). Pathological gambling was initially recognized as an impulse control disorder in the third edition of the Diagnostic and Statistical Manual (DSM-III, 1980) of the American Psychiatric Association (APA). Prior to 1980 courts were reluctant to recognize gambling addiction as a mitigating factor that impinged on a person's ability to control her/his wrongful behavior. Rather, they treated it in the same manner as alcohol and drug addiction, neither of which was recognized under diminished capacity guidelines.

With the inclusion of pathological gambling as a mental disorder in the DSM-III, the courts became more receptive to a defence that incorporated gambling addiction. The approach was controversial, however, as legal experts expressed concern about misuse, arguing: a) the DSM-III was "a clinical, and not a legal, document" (Castellani, 2000: 54), and therefore should carry little weight in court; b) that gambling addicted offenders would receive unduly light sentences; and c) that the DSM-III had been premature in its classification of pathological gambling and, therefore, the courts 
should await wider consideration and acceptance by the scientific community (Geis, 2004: 350).

The gambling addiction defence gained increasing support as diagnostic revisions were introduced, first in the DSM-III-R (1991) and subsequently the DSM-IV (1994) and DSM-V (2013). Of note, the most recent revision relocated pathological gambling to "Substance Use and Addicted Disorders" marking the first ever inclusion of a non-substance (or "behavioral") addiction. Thus, the APA's evolving recognition of pathological gambling opened the way to using the gambling addiction defence in criminal trials and the engagement of expert witnesses as resources to the court.

\section{SENTENCING CONSIDERATIONS}

Given that accused problem gamblers invariably admit their guilt, defence lawyers turn their attention to sentencing and the mitigating link between gambling addiction and the crime. As noted earlier, Canadian courts did not view gambling as an addiction disorder until recently, nor were judges likely to understand the addictive nature of EGMs (Harrigan and MacLaren, 2011). Defence attorneys contributed significantly to such gains by introducing evidence of gambling-related harm that preceded illegal activity, including depleted bank accounts and retirement savings, maximized credit card debt, and encumbered property. In so doing, they argued that the accused's self-control was substantially impaired well before the criminal act and, for context, described states of heightened anxiety and desperation. As mentioned, loyalty program data has been introduced more recently; augmenting mitigation arguments by outlining a culture of inducement that can abet and exploit gambler vulnerabilities.

Although not an exculpatory criminal defence in Canada, gambling addiction is increasingly considered in sentencing, where judges deliberate the nature and context of the crime along with any aggravating or mitigating factors (Beresh, 2002: 16). In so doing, they consider the relative emphasis to be placed on the principles of punishment, deterrence, denunciation, and rehabilitation (Allen Consulting Group, 2011: 16). Aggravating factors typically include the amount of money taken, whether breach of trust or violence was involved, the length of time and number of occasions over which the criminal acts occurred, and who was victimized. Mitigating factors might include the specifics of the accused's addiction, the degree of remorse, willingness to make restitution, and level of engagement in treatment. An emerging frontier further considers the contribution of the gambling provider in prompting, maintaining, and exacerbating the gambling addiction and considering the extent to which the accused was exploited or victimized.

Sentences for more serious offences tend to emphasize punishment and deterrence, usually expressed through longer prison terms. Gambling addiction notwithstanding, the court recognizes its broad duty to denounce the crime and deter other potential offenders ${ }^{4}$. Rehabilitative sentences, known in Canada as conditional sentences, are increasingly common. Introduced in 1995 in response to prison overcrowding, conditional sentencing entails noncustodial punishment for offenders who present little or no threat to the community. Conditions may be attached which, in gambling-related cases, include curfews, mandatory treatment, gambling prohibition, community service, and restitution. A breach of conditions is likely to result in an order to complete the sentence in prison.

\section{ROLE OF THE EXPERT WITNESS}

The overall role of the expert witness for the defendant is to provide evidence-based information about gambling addiction that is specific to the facts of the case and unlikely to be known to the judge and/or prosecutor. The expert is permitted to offer opinion in the course of testimony and, in so doing, to comment on gambling addiction as a mitigating factor. Although adversarial expert testimony is rare in these criminal trials, crown attorneys may aggressively cross-examine in an effort to counter suggestions that the accused was not solely responsible for his or her actions. ${ }^{5}$

In determining whether to retain an expert witness, defence attorneys must consider: a) cost - addicted gamblers typically are short of funds; b) whether there is a suitable candidate who can articulate his/her knowledge effectively and withstand cross examination; and $\mathrm{c}$ ), the likelihood that expert analysis will positively affect the sentence. If the decision is to proceed, the

\footnotetext{
${ }^{4}$ Of note in this regard is that non-addicted gamblers are highly unlikely to commit gambling-related crimes. On the other hand, addicted gamblers by definition are experiencing a combination of impaired control and desperation levels of anxiety and distress. Under such circumstances, they tend to act out of character by violating laws (and attendant penalties) which they are fully aware exist (Taylor, 2004)

${ }^{5}$ In civil trials, the defence (usually the gambling provider) invariably introduces expert testimony of its own, which tends to discredit both the plaintiffs expert and that person's proffered opinion. Although experts are, in some provinces, required to sign declarations of neutrality and singular allegiance to the court, rigorous compliance remains elusive.
} 
attorney will typically seek a university-based gambling researcher or a gambling addiction treatment specialist (often a psychologist or psychiatrist), bearing in mind that the expert must be qualified as such through formal review and acceptance by the trier of fact.

Expert witnesses usually contribute in two ways: by providing an assessment of the clinical status of the accused, and by describing the gambling-related contextual circumstances of the crime. A single expert might address both functions or two might be separately engaged.

In relation to clinical assessment, the expert conducts an in-depth interview to determine the diagnostic status of the accused, supplemented with accompanying rationale, relevant health history, and the psychosocial context surrounding the criminal behavior. Also assessed is the accused's emotional state and extent of remorse, and finally, any steps taken toward rehabilitation are documented. Overall, the goal is to provide insight into the thought processes and mental state of the accused that culminated in a transition to illegal behavior. The clinical assessment is essential to the proceedings, as the crime of a gambling-addicted offender may otherwise appear no different than one motivated solely by greed (Beresh, 2002).

In describing the contextual circumstances for the crime, the expert draws upon the research literature to explain the onset and progression of problem gambling, and how problems are compounded and exacerbated over time. These explanations focus on both the individual gambler and the contribution of the gambling environment.

In relation to the individual, the expert typically describes the underlying risk factors such as erroneous cognitions; risky gambling practices (e.g., chasing losses); and preoccupation with gambling, and how each directly contributes to increasingly heavy gambling and losses. Next the elements of problem gambling are described, including impaired control, negative consequences, and persistence with unsustainable gambling. Consistent with this overview, the expert reconstructs the specific experience of the accused, including her/his transition to the emotionallydriven state of heightened anxiety and desperation which precipitated the criminal behavior.

The expert may also describe the contribution of the gambling environment to the onset and progression of problem gambling. Of particular interest are the features of EGMs that are designed to mislead gamblers and induce excessive play ${ }^{6}$. If the accused was a member of a gambling venue loyalty program, the expert can review detailed data base records, which include the frequency of play, the duration of each session, the average bet size per session, and the history of net losses per session and cumulatively. These metrics often show a transition from initially benign gambling to serious over-involvement in time and money spent, and makes explicit the growing magnitude of losses. Further to records of escalating play and loss, the expert might describe the appeals of the provider to generate more gambling, including personalized communications and inducements tailored to the accused's response patterns ${ }^{7}$.

As mentioned, the expert is permitted to proffer opinion and, in this regard, might comment on whether the accused was systematically cultivated through the loyalty program to lose the maximum amount of money possible despite reasonable evidence of foreseeable distress (Orford, 2011; Simpson, 2012: 6).

\section{GOVERNMENT'S CONTRIBUTION TO PROBLEM GAMBLING}

A unique feature of gambling in Canada is that provincial governments, as the sole providers of gambling and through their singular focus on gambling revenue, are complicit in fostering EGM addiction. The aforementioned REVPAC is not only the gold standard for EGM performance (Dow Schull, 2012: 21), but also defines the expected revenue per machine. As such, it becomes the principal criterion for government purchases-simply put, an EGM that produces $\$ 2,500$ per day trumps one that generates only half that amount. The inescapable contribution of high REVPAC machines to addiction and harm is the inconvenient baggage of such purchasing decisions. Thus, governments face a perverse incentive of having to choose between minimizing harm and maximizing revenue. Ironically, in response to a similar dilemma

\footnotetext{
${ }^{6}$ For example, winning outcomes in Ontario are programmed to appear above and below the actual pay line 12 times more frequently than a win actually occurs. When sounds are set off announcing a win, the amount won is less than the amount bet as much as $60 \%$ of the time; stop buttons give the illusion that the gambler can influence outcomes even though they have been preprogrammed (Dixon, Harrigan, Sandhu, Collins, and Fugelsang, 2010).

Loyalty program members with heavy losses are known to have received monthly personal letters from casino CEOs or dedicated handlers wishing family members well, thanking recipients for placing trust in the casino, offering complimentary tickets to casino entertainment, overnight hotel stay and limousine transport, and coupons for $\$ 500$ in matched bets should they choose to gamble while there.
} 
these same governments enact liquor laws that prohibit licensed premises from maximizing revenue by serving patrons to intoxication.

Provinces have addressed the revenue versus harm quandary by designating it an "issue management" matter that includes trumpeting the "responses" they have put in place. Although ostensibly intended to contain the harm from EGM play, ${ }^{8}$ these responses enjoy little or no empirical evidence of effectiveness, while other measures that are known to be effective are steadfastly avoided (Williams, West and Simpson, 2012). Wilful blindness precludes provincial governments from recognizing that they can prevent harm only through the imposition of legislative and regulatory limits on the very attributes that produce high REVPAC ratings.

\section{SUGGESTED WAYS TO REMEDIATE THE PLIGHT OF ADDICTED GAMBLERS THAT RESORT TO CRIMINAL BEHAVIOR}

Based on our experience, gambling-addicted offenders do not present as stereotypical criminals. Generally, they act embarrassed, ashamed, and contrite. We found it disheartening to see people with no criminal history or prior inclination, forfeit their finances, families, jobs, reputations, personal morality, and self-respect. In this regard, Adams (2008) postulates that modern day gambling regimes contribute to subtle degradations in democracy, in that civic virtues such as tolerance, compassion, justice, and the common good become less relevant when profit enhancement is the major objective.

Castellani (2000) argued that the American criminal justice system needed clarification with respect to its treatment of problem gamblers. In his view American courts were overly dependent on the medical model; that is, a belief that gambling addiction is primarily a medical disorder caused by a dysfunction within the person. This narrow view vigorously supported by gambling interests, has essentially precluded consideration by the courts of the roles played by government and gambling providers (Hing, 2002).

\footnotetext{
${ }^{8}$ Examples of social responsibility initiatives used on EGMs in Canada include: educational campaigns and slogans; intervention training for gambling venue employees; equipping EGMs with 'responsible gambling features' such as clocks, cumulative wagering totals, and slowing the speed of play; capping and/or reducing the number of EGMs provincially, regionally or by establishment; abolishing retailer incentive systems based on EGM yearly revenue totals, and allowing communities to vote on whether to retain or remove EGMs (Smith and Campbell, 2007: 93).
}

In counterpoint to the medical model perspective, it is clear that stronger regulatory controls over the addiction-promoting aspects of EGM play could spare many gamblers from the extreme financial harm that can lead to criminal acts. Examples of such controls include, a) mandatory use of 'smart cards' which require pre-committing to reasonable time and spending limits per session and include algorithms which identify gamblers in distress (Schellinck and Schrans, 2011); b) lower bet limits--the Productivity Commission (2010) recommended a maximum EGM bet of $\$ 1$ as the highest priority for reducing gambling problems; and c), eliminating bill acceptors on EGMs and removing bank machines from venues, as both are believed to encourage excessive play (Dow Schull, 2012: 272).

Addressing collateral damage is another sphere where the court's response to the financial crimes of addicted gamblers could be enhanced. Of particular note are the victims from whom money has been illegally taken-such funds can accurately be viewed as proceeds of crime that have been transferred to the gambling provider. In general terms, these funds are divided between operators and provincial governments which, despite their criminal origins, retain them. This circumstance raises the question posed by Cormack and Cosgrave $(2013,170)$; namely, what is the role of the state with regard to excessive gambling? Is the state a protector or an enabler? The greater interests of justice might be better served if these funds were returned to the victims of the crimes. It must be considered that gambling providers acquired the funds through one-sided odds, deceptive EGM design and, should the gambler have been a loyalty program member, exploitation. Moreover, since providers do not forfeit tangible goods to acquire the funds, a case can be made that they would not be unfairly or unduly harmed by having to return them to the victims of the crime.

Collateral damage issues we observed created complications that are outside the narrow purview of the justice system. For example, an offender's spouse, children, and employers are innocent victims that face severe financial setbacks as well as emotional stress, yet receive no compensation. In one case a husband who went to jail for embezzling $\$ 200,000$ from his employer to feed his EGM addiction, resulted in the wife taking on two jobs to support the family and the children needing counseling because of the family upheaval. We also saw an employer lose his small business because of a trusted employee's fraudulent 
activities and an incarcerated gambling addicted single mother impose on relatives to take care of her children. Instances like these leave unanswered questions not usually dealt with by justice system. For example, is the family responsible for paying the offender's debts? Can a victimized employer sue for damages?

On another front, consideration should be given to applying the therapeutic jurisprudence model in dealing with gambling-related criminal activity. The underlying principle of which is for legal processes to incorporate therapeutic goals rather than emphasizing punishment (Luther, Mela \& Bae, 2013). This collaboration between law and psychiatry focuses on the causes of criminal behavior by offering treatment to help offenders become productive citizens (Guenaga, 2013: 138).

Inspired by drug addiction, domestic violence, and mental health courts, three jurisdictions (New York, Louisiana, and Nevada) have established gambling courts. Acknowledging that problem gambling is a psychiatric disorder, these courts allow medicallyscreened offenders (not all qualify; for example, violent offenders, domestic and child abusers) to enter supervised care. Under court order, offenders are required to abstain from gambling and engage in formal treatment. This can occur either in a correctional institution or as an outpatient with a deferred sentence, and is often supplemented by requirements for community service and restitution to victims. Successful completion of the program allows the conviction to be set aside; however, should conditions not be met, a prison sentence could be imposed. There is some evidence that gambling courts reduce recidivism and change public perceptions of problem gambling "from a character flaw which must be punished to an illness or addiction that must be treated" (Guenaga, 2013: 147). Although some Canadian courts have shown leniency through conditional sentencing, formal gambling courts have yet to be established.

In summary, it is evident that changes to the DSM since 1980 have facilitated the efforts of defence lawyers to establish gambling addiction as a mitigating factor in criminal trials. However, our experience in these proceedings suggests that much remains to be accomplished, particularly in regard to the circumstances that contribute to gambling-related financial crime and the response of the criminal justice system. Suggested improvements include a) gamblingspecific consumer protection measures; b) regulatory control over the addictive elements of EGM play; c) the introduction of gambling courts; and d) a legislated duty of care owed by gambling providers to EGM players.

\section{REFERENCES}

Adams, Peter. (2008). Gambling, Freedom and Democracy. New York: Routledge.

Alberta Gaming and Liquor Commission Annual Report. (2012-2013). St. Albert, AB.

Allen Consulting Group. (2011). Responding to Gambling-related Crime. Report to the Tasmanian Government Department of Treasury and Finance, Hobart, AU.

American Psychiatric Association. (1980). Washington DC: Diagnostic and Statistical Manual-III.

American Psychiatric Association. (1991). Washington, DC: Diagnostic and Statistical Manual-IIIR.

American Psychiatric Association. (1994). Washington, DC: Diagnostic and Statistical Manual-IV.

American Psychiatric Association. (2013). Washington, DC: Diagnostic and Statistical Manual-V.

Beresh, Brian. (2002). "Defending the Gambling Addict." Presentation to the Alberta Gambling Research Institute annual conference, April, Edmonton, AB.

Borrell, Jennifer. (2006). Critical Commentary by an EGM Gambler, October 2004: Introduction by Jennifer Borrell. International Journal of Mental Health Addiction, 4: 181-188. http://dx.doi.org/10.1007/s11469-006-9013-0

Canadian Gambling Digest. (2011-2012). Toronto, ON: Canadian Partnership for Responsible Gambling.

Castellani, Brian. (2000). Pathological Gambling: The Making of a Medical Problem. Albany. NY: State University of New York Press.

Cormack, Patricia., \& James Cosgrave. (2013). Desiring Canada. Toronto, ON: University of Toronto Press.

Delfabbro, Paul, \& Anthony Winefield. (2000). "Predictors of Irrational Thinking in Regular Slot Machine Players." Journal of Psychology, 134: 117-128. http://dx.doi.org/10.1080/00223980009600854

Dixon, Mike, Harrigan, Kevin, Sandhu, Rajwan, Collins, Karen, \& Jonathan Fugelsang. (2010). "Losses Disguised as Wins in Modern Multi-line Video Slot Machines." Addiction, 105(10): 1819-1824 http://dx.doi.org/10.1111/j.1360-0443.2010.03050.x

Dow Schull, Natasha. (2012). Addiction by Design. Princeton, NJ: Princeton University Press.

Geis, Gilbert. (2004). "Pathological Gambling and Insanity, Diminished Capacity, Dischargeability, and Downward Sentencing Departures." Gaming law Review, 8(6): 347-360. http://dx.doi.org/10.1089/glr.2004.8.347

Guenaga, Amaia. (2011). "Improving the Odds: Changing the Perception of Problem Gambling and Supporting the Growth of Problem Gambling Courts." UNLV Gaming Law Journal, 2(1): 133-154.

Harrigan, Kevin, \& Vance MacLaren. (2011). The House Rules: Gaming Regulations and Their Effects on Gambling and Problem Gambling Across Canada. Guelph, ON: Report prepared for the Ontario Problem Gambling Research Centre.

Harrigan, Kevin, MacLaren, Vance, Brown, Dan, Dixon, Mike, \& Charles Livingstone. (2014). "Games of Chance or Masters of Illusion: Multiline Slots Design May Promote Cognitive Distortions." International Gambling Studies, accessed May 22, 2014.

http://dx.doi.org/10.1080/14459795.2014.918163 
Hing, Nerilee. (2002). "The Emergence of Problem Gambling as a Corporate Social Issue in Australia." International Gambling Studies, 2(1): 101-122. http://dx.doi.org/10.1080/14459790208732302

Institute for American Values. (2013). Why Casinos Matter; Thirtyone Evidence-based Propositions from the Health and Social Sciences. www.americanvalues.org retrieved Oct. 16, 2013.

Livingstone, Charles. (2005). "Desire and the Consumption of Danger: Electronic Gambling Machines and the Commodification of Interiority." Addiction Research and Theory, 13(6): 523-534. http://dx.doi.org/10.1080/16066350500338161

Livingstone, Charles, \& Richard Woolley. (2007). "Risky Business: A Few Provocations on the Regulation of Electronic Gaming Machines." International Gambling Studies, 7(3): 361-376. http://dx.doi.org/10.1080/14459790701601810

Luther, Glen, Mansfield Mela, \& Victoria Bae. (2013). Literature Review on Therapeutic Justice and Problem Solving Courts. Saskatoon, SK: University of Saskatchewan Faculty of Law.

Munoz, Yaromir, Chebat, Jean-Charles, \& Jacob Ammon Suissa. (2010). "Using Fear Appeals in Warning Labels to Promote Responsible Gambling Among VLT Players: The Key Role of Depth Information Processing." Journal of Gambling Studies, 26: 593-609.

http://dx.doi.org/10.1007/s10899-010-9182-4

Ontario Lottery Gaming Corporation http://www.olg.ca/slotscasinos/default.jsp?page=winners_circle\&ref=home_menu Accessed Mar. 6, 2014.

Orford, Jim. (2009). "Governments as Promoters of Dangerous Consumptions." Addiction, 104: 693-694. http://dx.doi.org/10.1111/j.1360-0443.2008.02495.x

Orford, Jim. (2011). An Unsafe Bet? The Dangerous Rise of Gambling and the Debate we should be having. Chichester, UK: John Wiley \& Sons.

Parke, Jonathan, \& Mark Griffiths. (2006). "The Psychology of the Fruit Machine: The Role of Structural Characteristics (Revisited)." International Journal of Mental Health and Addiction, 4: 151-179. http://dx.doi.org/10.1007/s11469-006-9014-z

Perrone, Santina, Jansons, Deborah, \& Lisa Morrison. (2013). Problem Gambling and the Criminal Justice System. Melbourne, Vic: A report prepared for the Victorian Responsible Gambling Foundation,

Priest, Lisa. (Oct. 5, 2009). "Losing Big Losing Often." Toronto Globe and Mail. http://www.theglobeandmail.com/news/national/ the-million-dollar-club-losing-big-losing-often/article1311827/ Accessed Feb. 28, 2014

Productivity Commission. (2010). Australia's Gambling Industries. Canberra: Commonwealth of Australia.

Samson, Robin. (2004). "Compulsive Gambling as a Criminal Excuse Under the Federal Sentencing Guidelines." Gaming Law Review, 8(6): 361-370.

http://dx.doi.org/10.1089/glr.2004.8.361

Sasso, William, \& Jasminka Kalajdzic. (2006). Do Ontario and its Gambling Venues Owe a Duty of Care to Problem Gamblers? Guelph, ON: Final report, Ontario Problem Gambling Research Centre.
Schellinck, Tony, \& Tracy Schrans. (2011). "Intelligent Design: How to Model Gambler Risk Assessment by Using Loyalty Tracking Data." Journal of Gambling Issues, 26: 51-68. http://dx.doi.org/10.4309/jgi.2011.26.5

Simpson, Robert. (2004). "The Liability Debates." NewsLink. Toronto, ON: Responsible Gambling Council.

Simpson, Robert. (2012). "Gambling: A Unique Policy Challenge." Healthcare Quarterly, 15(4): 6-8.

Smith, Garry, Wynne, Harold, and Tim Hartnagel. (2003) Examining Police Records to Assess Gambling Impacts: A Study of Gambling-related Crime in the City of Edmonton. Edmonton, AB: A report prepared for the Alberta Gaming research Institute,

Smith, Garry, \& Colin Campbell. (2007). "Tensions and Contentions: An Examination of Electronic Gaming Issues in Canada." American Behavioral Scientist, 51(1), 86-101. http://dx.doi.org/10.1177/0002764207304854

Smith, Garry, \& Dan Rubinstein. (2011). "Socially Responsible and Accountable Gambling in the Public Interest." Journal of Gambling Issues, 25: 54-67. http://dx.doi.org/10.4309/jgi.2011.25.5

Starr, Justin. (2003). "Diminished Capacity Departures for Compulsive Gambling: Punishing the Pathological or Pardoning the Common Criminal." BYU Law Review, 1: 385418.

Storer, John, Abbott, Max, \& Judith Stubbs. (2009). "Access or Adaptation? A Meta-analysis of Problem Gambling Prevalence in Australia and New Zealand with Respect to Concentration of Electronic Gambling Machines." International Gambling Studies, 9(3): 225-244. http://dx.doi.org/10.1080/14459790903257981

Taylor, Gregory. (2004). "Is Addiction to Gambling Relevant in Sentencing?" Criminal Law Journal, 28(3): 141-159.

Thomas, Anna, Sullivan, Gavin, \& Felicity Allen. (2009). "A Theoretical Model of EGM Problem Gambling: More Than a Cognitive Escape." International Journal of Mental Health Addiction, 7: 97-107.

http://dx.doi.org/10.1007/s11469-008-9152-6

Turner, Nigel, \& Roger Horbay. (2004). "How do Slot Machines and Other Electronic Gambling Machines Really Work?" Journal of Gambling Issues, 11: 1-42.

Wheeler, Sarah, Round, David, \& John Wilson. (2011). "The Relationship between Crime and Electronic Gaming Expenditure: Evidence from Victoria, Australia." Journal of Quantitative Criminology, 27: 315-338. http://dx.doi.org/10.1007/s10940-010-9123-5

Williams, Rob, Belanger, Yale, \& Jennifer Arthur. (2011). Gambling in Alberta: History, Current Status, and Socioeconomic Impacts. Edmonton, AB: Report prepared for the Alberta Gambling Research Institute,

Williams, Rob, West, Bev, \& Robert Simpson. (2012). Prevention of Problem Gambling: A Comprehensive Review of the Evidence and Identified Best Practices. Guelph, ON: Report prepared for the Ontario Problem Gambling Research Centre.

(c) 2014 Smith and Simpson; Licensee Lifescience Global.

This is an open access article licensed under the terms of the Creative Commons Attribution Non-Commercial License (http://creativecommons.org/licenses/by-nc/3.0/) which permits unrestricted, non-commercial use, distribution and reproduction in any medium, provided the work is properly cited. 